\title{
Bridging Musical Worlds: Musical Collaboration Between Student Musician- Educators and South Sudanese Australian Youth
}

\author{
Kathryn Marsh, Catherine Ingram, and Samantha Dieckmann
}

\begin{abstract}
This chapter reports results of an innovative contemporary model of applied urban ethnomusicological research investigating the effects of collaborative musical engagement between students from the Sydney Conservatorium of Music (SCM) and South Sudanese Australian youth in the culturally diverse metropolis of Sydney, Australia. The Bridging Musical Worlds project was conducted in 2016 during a period of extraordinary global migration. In Australia, children and young people of South Sudanese heritage occupy a prominent place in emerging communities in many large urban areas but are often subject to discriminatory discourse. The project enabled SCM music education students to engage in reciprocal teaching and learning opportunities relating to South Sudanese music and culture and globalised popular music. In this chapter we outline the major outcomes of the project, including social inclusion through collaborative participatory music making, and explore the impact of these musical activities on the development of cultural competence and intercultural understanding for tertiary students.
\end{abstract}

Keywords Applied urban ethnomusicology · Cultural competence $\cdot$ Intercultural understanding · Preservice music education · Service learning

\section{Introduction}

The role of the ethnomusicologist-teacher educator has resulted in particular approaches to the training of music teachers in a number of tertiary institutions internationally. Many university music departments around the world involve students in music ensembles taught by musicians who are experts in particular cultural

K. Marsh $(\bowtie) \cdot C$. Ingram

Sydney Conservatorium of Music, The University of Sydney, Sydney, Australia

e-mail: kathryn.marsh@sydney.edu.au; catherine.ingram@sydney.edu.au

S. Dieckmann

Faculty of Music, University of Oxford, Oxford, UK

e-mail: samantha.dieckmann@music.ox.ac.uk

H. Westerlund et al. (eds.), Visions for Intercultural Music Teacher Education, Landscapes: the Arts, Aesthetics, and Education 26,

https://doi.org/10.1007/978-3-030-21029-8_8 
traditions, or offer service learning opportunities entailing students travelling to remote or overseas locations to interact musically with people living in these areas (e.g. Bartleet et al. 2014, 2016; Broeske-Danielsen 2013; Campbell 2010; Robinson 2005; Westerlund et al. 2015; Wiggins 2005). This chapter outlines the outcomes of an innovative contemporary model for applied urban, musical ethnographic research, involving a conjunction between applied ethnomusicology and service learning of tertiary music students, with particular reference to a case study of a recent collaborative research and teaching project undertaken with undergraduate music teacher-education students at the Sydney Conservatorium of Music (SCM), University of Sydney, Australia.

\section{Institutional Context}

SCM provides a range of undergraduate and postgraduate programs in performance, composition, musicology and music education. The 4-year undergraduate music education degree program at SCM, the Bachelor of Music (Music Education), aims to train prospective music teachers for future employment, principally in secondary schools. In the state of New South Wales (NSW) in which Sydney is located, the teaching of music is mandated at both primary and secondary levels (for students aged 5-12 years and 12-18 years, respectively), ${ }^{1}$ meaning that graduates of the SCM music education program are prepared by course content and in-school practice teaching placements to teach school students from 5 to 18 years of age, with an emphasis on the secondary level.

For many years, the music education degree program at this institution has encompassed a range of learning experiences reflecting the strong disposition of the program's teacher-educators, who are responsible for facilitating the development of students' intercultural understanding. Students' learning experiences are delineated within program content, including specific subjects focused on cultural diversity in music education, Australian Indigenous musics, Balinese gamelan (Dunbar-Hall 2009) and other Asian music ensembles (including the recently established Chinese Music Ensemble), which may be studied as an elective. The majority of these subjects to a greater or lesser degree involve direct interaction with culturebearers, both inside and beyond the institutional context of SCM, who teach about specific aspects of their music and its sociocultural import. There have been additional opportunities for students to engage further, for example, by participating in overseas modes of delivery of units on Balinese music and dance (Dunbar-Hall 2012; Rowley and Dunbar-Hall 2013).

\footnotetext{
${ }^{1}$ There is a mandatory $100 \mathrm{~h}$ of Music tuition for all students in the junior secondary school in NSW, after which students can elect to study Music either up to Year 10, and/or as a senior subject for the Higher School Certificate (HSC). Learning activities include performance, composition, listening and musicological study across a range of musical contexts and styles.
} 
To a large extent such initiatives have been driven by the highly multicultural nature of Australian society. As a nation that has been established and expanded through successive waves of immigration, both voluntary and involuntary, Australia is highly culturally and linguistically diverse, with a population identifying with more than 270 ancestries and speaking more than 260 languages, including those of Australian First Peoples (Department of Immigration and Citizenship 2011).

These initiatives have also developed as a result of the dual identities of the SCM teacher-educators, several of whom are also ethnomusicological researchers. The imperative for inclusion of field research with people representing minority cultures in Australia has underpinned content and assessment in at least one mandatory subject for trainee teachers for nearly two decades (Marsh 2005). Prospects for developing learning experiences of this kind have increasingly been enhanced as strong collaborative partnerships between staff members of SCM with ethnomusicological and pedagogical expertise have continued to emerge.

Impetus has also come from The University of Sydney Strategic Plan, which sees the development of cultural competence - that is, the ability "to work productively, collaboratively and openly in diverse groups and across cultural boundaries" (The University of Sydney 2016, 32) - as inherent to the university educational experience of all students. The university has sought to "Embed cultural competence as a learning outcome in every degree ...; provide meaningful learning activities that take advantage of the cultural diversity within the University community, including group projects requiring collaboration skills; [and] ensure that professional programs develop cultural understanding and intercultural capabilities relevant to likely practice" (The University of Sydney 2016, 58). In this chapter we acknowledge that intercultural competence may be defined in multiple ways (Deardorff 2006), but for ease of discussion adopt the university's designation provided above, in conjunction with the more nuanced definition provided by Deardorff: "the ability to communicate effectively and appropriately in intercultural situations based on one's intercultural knowledge, skills, and attitudes" (2006, 247-248).

Just as cultural competence is deemed to be one of the six required "graduate qualities" of students of the University of Sydney, intercultural understanding is one of the planned cross-curricular "general capabilities." These general capabilities are outcomes of the Australian Curriculum, which states that "Intercultural understanding involves students learning about and engaging with diverse cultures in ways that recognise commonalities and differences, create connections with others and cultivate mutual respect" (Australian Curriculum Assessment and Reporting Authority n.d.). Implicit in such definitions is an understanding that the term, 'intercultural' must also acknowledge "the complexity of locations, identities and modes of expression in a global world, and the desire to raise awareness, foster intercultural dialogue and facilitate understanding across and between cultures" (Burnard et al. 2016, 1-2). Thus, general curricular directives both in relation to the training of teaching graduates and their concomitant implementation of school curriculum require the development of cultural competence and intercultural understanding in SCM music education students. 
In implementing such directives within an institutional framework, the ongoing practices of the music education program and the specific project discussed in this chapter are in keeping with cross-curricular approaches to intercultural communicative competence found at all levels of education that involve "being able to change perspectives, empathy, openness and willingness to interact in culturally diverse contexts" (Leh et al. 2015, 100). These practices also reflect philosophies of intercultural music education that are articulated by Carson and Westvall, who see the various forms of engagement with "diversified normality" as "transformative aspects of education" $(2016,29)$. Such engagement is mutually beneficial for students within institutions and the members of the multiple communities with which they engage, in that it creates

spaces for intercultural dialogues that, rather than promoting assimilation, allow for richer modes of interaction. This happens from all sides. It is not merely that individuals from marginalized communities need to be able to develop the skills necessary to engage with the dominant group's values, but all agents should aim to cultivate a view of society that includes difference and variety as fundamental aspects. (Carson and Westvall 2016, 39)

Carson and Westvall (2016) see that such approaches reduce boundaries between institutions and communities and involve broader and more flexible definitions of what constitutes "community." In addition, recent demographic changes, both within Australia and globally, necessitate more urgent and further enhancement of cultural competence and intercultural understanding in the educators of the future. As Jones argues, music education has particular potential to address the challenges of such cultural diversification since music "serves as a perfect mediating space ... [to] develop a sense of shared identity and intercultural understanding ... [and] teach skills for democratic action such as leading and following, teamwork, debate, [and] compromise" $(2010,295)$. Despite the long-established advocacy for intercultural music education at all levels (see e.g. Oehrle 1996; O’Flynn 2005), questions remain regarding how music teachers can best be prepared to realize these visions.

\section{Constructing Intercultural Music Teacher Education}

Although academic coursework and in-school placements are central to music teacher education, research has shown that the development of intercultural understanding requires additional, and intentionally framed, experiences with cultural diversity (Emmanuel 2005). Even where tertiary educators and curricula promote the inclusion of culturally diverse music materials by preservice teachers, the use of such content is rarely modelled for them in primary and secondary placements (Joseph and Southcott 2009). This lack of in situ experience perpetuates the exclusion of multicultural musics from the classroom. However, training preservice music teachers to work with heterogeneous student populations in contexts that may vary greatly from their own educational upbringing moves beyond the inclusion of culturally diverse music content. Teaching in these complex, and for some 
confronting, situations requires a high level of pedagogical reflexivity informed and enabled by intercultural competence. It involves not only an expansion of notions of legitimate music education materials, but also continued reflection on what music education itself entails (Burton et al. 2012). Exploring the boundaries of music and music education directs attention towards some of the primary goals of intercultural teacher education more broadly: to shift future teachers from ethnocentric to ethnorelative ways of viewing the world, and to develop critical understandings of the "sociocultural dynamic of schooling that is the foundation of culturally-responsive teaching" (Marx and Moss 2011,36).

Marx and Moss (2011) suggest that conventional domestic in-school placements with culturally diverse student populations do not lend themselves to this sort of perspective transformation, noting that the wider educational system and culture within which most participating schools are encompassed only serve to reinforce the preservice teachers' sense of educational norms. Within such experiences, any 'difference' encountered in the student population can continue to be considered exceptional. Preservice teachers will tend to identify with the school and the teacher, and are not prompted to question the practices in which they have likely been enculturated throughout their own schooling experiences, some of which might negatively affect marginalized students. It is for this reason that tertiary intercultural education often involves immersion experiences, in which "students are put in situations where they have to learn to function within a different cultural context and among members of the host culture who perceive them as cultural others" (Marx and Moss 2011, 42). In the field of intercultural music teacher education, international exchange and cross-institutional collaboration projects have been found to be suitable contexts for such immersion (Broeske-Danielsen 2013; Brøske this volume; Burton et al. 2012; Kallio and Westerlund this volume; Sæther 2013).

The project described in the current chapter took an alternative approach to intercultural immersion. As will be explained, preservice music teachers were situated in a relatively local, community-based setting in which they (and the music education activities they implemented) were seen as culturally Other. Further, the students with whom they worked attended an excursion at the preservice teachers' tertiary institution, inviting reflection on the institute of the Conservatory - and, by extension, classical Western music education - as a 'different' cultural context. By structuring this exchange in its domestic setting, the project was positioned at the intersection of community, cultural diversity and institutionalized music education in the context of Sydney. In line with O'Flynn's argument that, "systems of music education best advance with due regard to the social realities in which that education takes place" $(2005,197)$, the project aimed to develop intercultural competences and understandings that were directly transferable to the settings of the preservice teachers' future employment. 


\section{The Bridging Musical Worlds Project}

The Bridging Musical Worlds project took place in early 2016, in the context of almost unprecedented global migration flows. Driven by flight from conflict, economic inequity and other factors, refugees and voluntary migrants sought resettlement in Europe, Sub-Saharan Africa, the Middle East, South East Asia, North America and Australia (UNHCR 2016). Among the many migrant groups who have settled in Australia, the South Sudanese Australian community represents a substantial proportion of newly arrived migrants and comprises many people who are refugees who have fled from continuing conflict in South Sudan. Members of this community identify with a diverse range of South Sudanese ethnicities and cultural groups, with South Sudanese Australian children and young people - many of whom were born in Australia or have lived most of their lives outside South Sudan occupying a prominent place in the communities in many large urban areas, including in Sydney (Cassity and Gow 2006; Dieckmann 2016; Westoby 2009). ${ }^{2}$

Child refugees are frequently viewed as victims of their traumatic circumstances, and psycho-social assistance is seen as a necessary requirement for their resettlement. For refugee and newly arrived immigrant children this often means provision of support by adult members of the dominant society to enhance social inclusion. However, while such support is undeniably valuable, more recent research indicates that children and young people who are refugees or voluntary migrants also function as agentive social actors, and may consciously employ strategies that assist with meeting their own emotional and social needs (Hart 2014). Recent studies point to the role of music in providing collaborative avenues for enhancing social inclusion, identity construction, and self-expression for young refugees and immigrants (Karlsen 2013; Marsh 2012, 2013, 2015, 2017; Marsh and Dieckmann 2016).

The Bridging Musical Worlds project aimed to investigate the effects of collaborative musical engagement between South Sudanese Australian youth and music education students from the Sydney Conservatorium of Music in relation to:

- Children and young people's musical engagement with activities, musical preferences, forms of self-expression and developing musical identities;

- The opportunities for social inclusion of children within participatory musical communities created by musical collaborations; and

- The opportunities for development of cultural competence and intercultural understanding provided by these activities for SCM students.

\footnotetext{
${ }^{2}$ Civil war between the north and south of Sudan has been endemic since Sudan obtained independence from Britain and Egypt in 1956. The initial refugee flows from South Sudan therefore predate 2011 when South Sudan gained independence from Sudan. However, continued conflict both in South Sudan and in southern and western regions of Sudan, including Darfur, South Kordofan and Blue Nile, has resulted in ongoing refugee flows and internal displacement of people from these areas (Cockett 2010; LeRiche and Arnold 2012). Thus, refugees and migrants from both South Sudan and Sudan have entered Australia over the past two decades (Refugee Council of Australia 2016).
} 
The engagement of South Sudanese Australian children and young people with creative music activity, in collaboration with students from the Sydney Conservatorium of Music, occurred under the auspices of the SCM and the Language Discovery (LD) ${ }^{3}$ Program in Sydney. The LD Program is a community-based literacy program for children and families of refugee backgrounds. It provides educational assistance and mentoring, and promotes social inclusion and support for children and families through a variety of means including special communal activities involving sport, music, dance and other youth-focused opportunities.

The collaboration came about through SCM ethnomusicologist Catherine Ingram's ongoing research into the music-making of South Sudanese Australians as a cultural minority group in Australia. In her research, Ingram is seeking to better understand how music may influence cultural minorities' engagement with their wider social context. She had also been involved as a volunteer with LD for more than 1 year, and had received an invitation from LD personnel to organize a program of music activities for a group of Sudanese Australian ${ }^{4}$ young people. Together with co-author Marsh, Ingram enlisted the services of SCM students in their final year of the music education degree, as part of their compulsory Cultural Diversity in Music Education (CDIME) unit of study (coordinated and taught by Marsh). The project subsequently evolved into an interactive, service-learning opportunity for the students to work with Sudanese Australian youth in Sydney. The 34 students enrolled in CDIME were offered the chance either to engage in the service-learning provision or in an alternative set of activities. All students chose to take part in at least the first and third service-learning activities at SCM (outlined below), while seven students volunteered to participate in the full set of service-learning activities at both SCM and LD.

The project involved the development and implementation of a program of creative music activities, focusing on the informal learning methods previously articulated by Green (2008) and Harwood and Marsh (2012), and also promoting active collaboration between the South Sudanese Australian youth and the SCM students. The project had a multifaceted approach, with the following components:

1. A preliminary experiential workshop at SCM provided by a South Sudanese Australian musician, Mary Mamour, to all SCM students in the final-year cohort. The workshop was intended to develop knowledge about South Sudanese music and culture, the ongoing violence that had precipitated the large migratory flows, and the experiences of South Sudanese Australians prior to and post migration to Australia, with the aim of enhancing initial cultural understanding. The workshop included immersive learning of Jieng (or Dinka) songs and dances

\footnotetext{
${ }^{3}$ For ethical reasons, "Language Discovery" and its acronym, "LD" are pseudonyms.

${ }^{4} \mathrm{LD}$ aims to fulfil educational needs of young people from both South Sudan and Sudan, though the majority of these young people are from what is now South Sudan or have parents from South Sudan. For this reason, the young people who took part in the LD activities are sometimes designated as South Sudanese Australian and sometimes Sudanese Australian. It should also be noted that not all young people in the program are newly arrived and some have been born in Australia to families who arrived as refugees.
} 
associated with everyday activities, Christian worship, and social occasions, using culturally relevant pedagogy. The workshop was supplemented by online written and audiovisual materials (provided by Ingram) relating to the abovementioned relevant cultural and social aspects.

2. A series of three Saturday afternoon workshops were conducted by the seven SCM student volunteers and Marsh with Sudanese Australian youth over a period of 4 weeks in the LD community setting, under the guidance of Ingram. Drawing on Marsh's (2013) prior research with South Sudanese Australian refugee children and Ingram's and Dieckmann's research and experience in the community (Dieckmann 2016; Ingram and Mamour 2016), the initial repertoire choice was designed to accommodate previously observed musical preferences of South Sudanese Australian children for particular genres of popular music, especially as performed by mainstream black artists whose songs are globally disseminated. The workshop sessions consisted of an initial performance by the SCM students of a popular song, as an aural and visual model, followed by predominantly aural learning of the vocal, guitar, ukulele, keyboard, bass and drum parts of the song in small instrument groupings. A separate set of creative activities was simultaneously offered for younger children. At the end of each workshop there was an informal performance of the learnt repertoire to the children's parents and LD coordinators and volunteers.

3. A half-day visit to SCM. This visit occurred in the school holidays during the project period, and the Sudanese Australian children and young people worked with the whole 4th-year Music Education cohort to develop their collaborative musical creations, recreations and performances in conjunction with SCM students. They also had a chance to observe performances of similar musical genres given by the SCM class group. The visit culminated in a performance of a popular song by all SCM students and LD young people, followed by brief stringedinstrument performances by SCM students, and a tour of SCM. In addition to the visit being intended to facilitate development of SCM students' cultural competence, it also enabled the Sudanese Australian young people to augment both their musical skills and experiences and their educational aspirations through collaborative interaction with the SCM students. The capacity for the enhancement of social inclusion through these various activities was increased by the presence of several parents, young siblings (who joined in the early childhood session) and other members of the related South Sudanese Australian community, including Mary Mamour (who led some unplanned, spontaneous singing at one point, as discussed later), in addition to the LD coordinators and volunteers. Forty-six Sudanese Australian participants, from infants to adults, participated in the visit.

Research methods for this project were influenced by the three authors' prior experience as ethnomusicologists employing ethnography as a principal form of research with members of the South Sudanese Australian community, and as music teachers in various educational settings. All acted as participant observers during the project. Data for this ethnographic case study were collected through observa- 
tions at both LD and SCM, interviews and informal conversations with participating SCM students, and research conversations with Sudanese Australian youth, parents, and other community members. Video recordings were made of Mary Mamour's sessions and the culminating performances of the SCM-LD workshop day, and the student interviews were audio and video recorded for later transcription. All student interviews were conducted on 4 May 2016, soon after the project had been completed. Documents in the form of email and Google Docs communications, preparation materials and written expressions of thanks were also collected as data.

The discussion in this chapter focuses on how the various project activities appeared to affect the SCM students, with the primary data source being the student interviews. The data were analyzed using grounded theory methods (Charmaz 2014; Corbin and Strauss 2008) and findings are outlined chronologically below according to resultant emergent themes.

\section{Understanding Participatory Music Making}

The broader results of the research, as outlined below, indicate that outcomes reported by preservice music teachers may not always align with those for which intercultural service learning programs are primarily designed: namely, the development of intercultural competence and understanding towards establishing reflexive and culturally-responsive teaching skills. Although developing SCM students' intercultural competence was one of the core aims of Bridging Musical Worlds, SCM student interviews revealed that, for the students, the practicalities and pedagogies involved in teaching music in a relatively unstructured community context were also very significant. The forms of cultural immersion and information provided by the initial parts of the project did not prepare the SCM students for the disjunct between the teaching and learning experiences that they had previously encountered in schools, and the more chaotic environment of a community setting, even though they had been briefed about its fluid nature and the students' need for flexibility:

Hailey: I knew that it wasn't going to be a really formal setting, from what they'd said. I think I expected to have a little more control, so it was a bit, it was a bit interesting going in and sort of, I think the first thing we saw was kids just running around this room screaming. And like, we'd put instruments down, they'd come run, pick up the instrument, run off with it and go outside. We're like, "No! That's really expensive!" .... Kids that were coming over with their lunch and using the djembes as a table for their pizza, and we're like, "Oh okay, alright. Well you know what, fine." So, you sort of had to let go of the, "This is what I want exactly to happen." And you've just got to be like, "Let's see what we can teach them in the time we've got, and just make it fun and enjoyable." So, once I'd accepted that, it was really great.

Sam: Letting go....

Hailey: Quite cathartic actually. 
Learning to 'let go' and act in a more facilitative role involved a change in orientation from focusing on a careful teaching sequence (for example, to develop a particular musical product or specific skill), to focusing on encouraging and engaging the students in musical participation. This change of orientation presented a considerable challenge that all of the students working in the LD setting articulated as their initial primary concern. It required an inclusive approach, as exemplified by Toby's reframing of his guitar activities with the LD young people:

by that stage it was more like, "Have a go. We can all have a go at the different guitars, and play around on the amps. I'll teach you some stuff but I think it's being able to get the instruments in your hands and being able to have a play at it" which was the main target, I think.

The adoption of this mode of action is in keeping with the tenets of community music practice, as outlined by Higgins, including the utilization of "flexible facilitation modes" and commitment to "multiple participant/facilitator relationships and processes" (Higgins 2012, 5). However, in the students' comments, there is also a developing acknowledgement of another characteristic of music-making in community settings - the recognition that "participants' social and personal growths are as important as their musical growth" (Higgins 2012, 5).

The social dimensions of musical participation have also been a primary concern in ethnomusicology in recent decades, as reflected in the title of Turino's (2008) seminal Music as Social Life: The Politics of Participation. Higgins's "multiple participant/facilitator relationships and processes" $(2012,5)$ resonate with what Turino terms "participatory performance," in which there are "only participants and potential participants performing different roles, and the primary goal is to involve the maximum number of people in some performance role" $(2008,26)$. Although Higgins is focusing on a pedagogical role, and Turino on a performative one, in reality, these both merge within the context of a participatory musical community. Participatory music making is described by Turino as an activity in which "stylized sound and motion are conceptualized most importantly as heightened social interaction. In participatory music making one's primary attention is on the activity, on the doing and on the other participants, rather than on an end product resulting from the activity" $(2008,28)$. Turino associates this form of music making with the development of "social synchrony" $(2008,41)$, entailing "a crucial underpinning of feelings of social comfort, belonging and identity" $(2008,44)$, to which this discussion returns below with a further examination of student responses to and outcomes of the project.

The tension between students' nascent awareness of music as integral to the social benefit of community and their developing intercultural understanding emerged when students were asked to explicitly address the intercultural aspects of the service learning program. They discussed both the pedagogical implications of the everyday music practices of the Sudanese Australian youth, and the ways that cultural and behavioral differences affected the interpersonal and relational dimensions of their teaching. 


\section{Understanding Music in the Lives of South Sudanese Australians: Pedagogical Implications}

For many years, the CDIME subject has, as a matter of course, encompassed the involvement of musicians who are a part of the culturally diverse Sydney environment. The rationale for this has been to enable students to understand that skilled musicians who can share their authentic knowledge of culturally contextualized music live within the local community and are not part of an exoticized Other. Students are encouraged to consider the benefits of involving musicians who may be seen as 'culture-bearers' within music education programs in schools to dispel stereotypical notions of music and culture and to experience the variability of 'authentic' musical experiences which may be related to folk, classical, popular, jazz, or fusion forms of musical and kinesthetic expression (Marsh 2005). However, the rationale for Mary Mamour's session as a form of preparation for the LD activities was not immediately apparent to some of the students.

Joseph: I'd say that Kathy wouldn't have brought in somebody from South Sudan to teach us, and, you know, spend a whole session on South Sudanese music without the intent of us getting something out of it. So, I knew we'd be getting something out of it, and I had absolutely, you know, I knew we would. I just couldn't see directly how it would relate to ... the LD project.

Partially, this lack of immediate perception of relevance was due to the seeming disjunct between the contemporary, mainstream popular music from the USA that was taught by SCM students (and favored by the young people from LD) and the kinds of repertoire performed and taught by Mary, which were in the Jieng language and ranged from traditional songs to newly composed Christian praise songs.

Julia: it was much more traditional music or religious music, whereas LD - we were told they love hip hop, they're young.... So that's what we stuck to.

The inclusion of contemporary popular music in the teaching repertoire was directed by the LD children themselves, following an informal survey of their musical preferences. However, research shows that while popular music from the UK and USA is significant in culturally and linguistically diverse students' lives, in private settings they also listen to international popular music connected to their families' languages and countries of origin, though sometimes in unpredictable ways (Carson and Westvall 2016; Karlsen 2013; Marsh 2012, 2013). Therefore, intercultural music education cannot solely involve content influenced by globalized media, which in itself establishes a type of "normative "comfort zone"" (Carson and Westvall 2016, 45), and must also include sustained engagement with a range of vernacular music practices (O’Flynn 2005).

The importance of understanding the broader implications of culture in a learning context was evident to some of the students following Mary's workshop. 
Julia: She [Mary] said a lot about her cultural context, I suppose. Like some of the lecture was just, her explaining about culture, about making baby handbags and stuff. Which was really interesting, we were, "Oh wow, we didn't expect this." Because we were expecting just music, but you can't put them in two categories. It's not mutually exclusive, like music and culture, like it is the same thing. So, I suppose in that way it made us realize, yeah, it's really important to them....

Jenny: I think it's always good to have background knowledge on the culture that you're going in, before. Yeah, sort of interacting with them and everything, just so that you can be culturally sensitive to what they may have experienced or what their parents have experienced.

Julia also discussed the information that Mary provided on the ongoing dislocation and trauma experienced by refugee families in the resettlement process, and the need to develop sensitivity to possible behavioral manifestations in the musiclearning context:

And she mentioned that some of them are, they're from broken homes, or their siblings have died.... Yeah and so we had to be quite sensitive to that. And sometimes [we] had kids crying because they couldn't play a drum, but part of you is like, "It's so much more than that. Their whole experience goes beyond that."

As the project developed, the students also began to recognize certain culturally congruent aspects of pedagogy utilized in Mary's workshop and their possible application in the LD setting. This was most evident in relation to imitative ways of learning, which were often structurally reinforced by call and response elements in the Jieng songs that were taught. Although learning by imitation was certainly practiced within some SCM music education subjects (especially in relation to forms of oral/aural musical teaching typical of informal learning), there was still a natural inclination for some students to rely on the more formal approaches that characterized Western classical music training in other areas of the SCM curriculum. Julia described her initial struggle to learn music with unfamiliar structures in this way:

Well she [Mary] taught us very differently.... She'd teach you vocally a melody or a rhythm, and ... it was really hard to let go. Let go of those formulated structures you're trying to find, and just kind of copy her and let it settle.... So, it was really different because it was all just about copying her, not about trying to analyze it, or whatever.

These methods of oral transmission, once accepted, were easily deployed for teaching song melodies, drum rhythms or guitar riffs to the young people from LD, as described by Toby:

Yeah, so the way Mary taught us to do, to sing and to do the songs that she was teaching us, I think was something we implemented in LD a little bit. Probably more the singers than me on the guitars, but at least with, like when we performed the songs it was very much just get everyone included because she would sing the line, and we'd sing it back, that kind of thing. And I think that would work very well with the LD group, because then you can jump straight into music without having to learn guitar or learn ukulele straight away. And with adding the percussion, I think that worked very well. 
Other SCM students working with the LD young people on a range of musical activities found the methods of teaching that they observed in Mary's session to be equally applicable throughout.

Hailey: Yeah, oh there was just little behavioral things. And she showed us videos of celebrations like weddings, and it was, I found that really interesting because it.... The learning experience, like... they'd shown us one video ... but it was, like they were all doing a dance together, and there was one person in the middle of them all that was leading the dance. And everyone just copied. She didn't say, "This is what you need to do, step, step, step, do it." It was just, she'd just do it and they'd play with it. So then I noticed, we did a similar thing with the drumming. We were just like, she'd just sing through the song and they'd copy us. And they'd respond to that much better than, "Play this rhythm," that would've just went over their head.

SCM students' perceptions of cultural behavioral norms, and the ways that they affected teacher-student interaction in the service-learning program, resonated with broader discussions about the rationale for and implementation of intercultural music education in tertiary settings.

\section{Music as Lived Experience: The Interpersonal/Relational Dimension}

The social dimensions of music making, as signifiers of varying aspects of culture and of lived experience, were conveyed to many students through the immersive experience of Mary's workshop, and had quite a profound effect on their understandings of culturally inclusive music education.

Ella: I thought it was a turning point for me. With this cultural diversity, I was like, "Well why are we doing this?" Like it didn't really click. "Why are we at this subject?" Until Kathy said, "It's really important that we explore different cultures." "Yes, yes." But then when Mary came in, it was like, "Oh! Okay that's why." Because you're actually getting someone from a different culture and it's really, I thought that was just a turning point.

Luke: It energizes you though, as well. To see someone live it.

It was especially interesting that Ella, who was bicultural, and who persuaded her Vietnamese mother to teach her to play the Dàn Tranh (a Vietnamese zither) for her presentation on her fieldwork project relating to music in her mother's life, had not initially recognized the need for cultural diversity in music education. Similarly, for Clea, one of the few interviewed students who had experienced a culturally diverse approach to music education in her secondary schooling, the personal engagement with Mary created an additional meaningful dimension to the experience.

Clea: It just gives you a bit more context, because a lot of the time - especially in high school - it felt like you were just ticking off the dot points.

Luke: Yeah, yeah. "Let's play African music."

Clea: You'd come to music and it'd be, "That's right, we have to do African music." And your Anglo-Saxon teacher will teach you it. It's not - like it's wonderful that it exists in the curriculum and that sort of thing, but it's not.... 
Ella: And they're giving it a go.

Clea: Oh yeah, that's wonderful, they're trying their hardest, but it gave a little bit of something more when some, a South Sudanese lady, Mary, actually came in and talked to us herself.

This immersive experience extended to the social interactions with South Sudanese Australian children and other members of the community on the day of the LD workshops at SCM. The main music education teaching room was packed with children, parents and other members of the community (including Mary Mamour) for the initial performances by the SCM students and the final combined performances. Following the small-group learning activities (held in various suitable locations outside the main music-education room), everyone returned to the main room for refreshments. The large number of people occupying the room created a certain level of apparent chaos that was unnerving for some students, but also provided an opportunity for interaction and engagement and further learning for others. In the very crowded and noisy space, Mary initiated some short impromptu performances of drumming, singing and dance, in which both children and parents, as well as some SCM students, participated sporadically at will, thereby extending upon previously established musical connections. During these activities, there was lively talking within and between the various groups. Julia, who participated in the weekend LD workshops, found this experience of holistic community engagement enlightening:

It was, I suppose that whole community aspect came into it a lot stronger because you have mums at the back making tea, at the back. And grandma's watching, and kids crying and it was so funny because they're so used to it, this is music for them. It's not meant to be on a stage, lights on, audience in darkness. Yeah, it's just the way they do it.

While these perceptions of engagement with culture were, perhaps, still somewhat essentialist in nature, it represented another example of Julia's significant realization of the non-dichotomous nature of music and culture, and the personal investment of members of the community in the multiple activities, mores and relationships that constitute culture. Hailey stated:

It was really nice ... even just seeing the way they interact with each other, and their parents, and seeing the way their parents interacted with each other, I sort of really enjoyed that aspect.

Jenny also commented on these interactions, but also on the relationships that were evidently developing between the SCM students and the Sudanese Australian young people as a result of the LD musical activities, even in the space of these few relatively short encounters. She noted:

Well I thought... it was just really interesting to see how they all engaged with each other, and to see... I mean, even after just one session, they were even pretty close to the people that went to LD.... And they were like, you could tell that they knew who they were, and that they were kind of more inclined to go towards them. But other than that, I think it was, it was great having them in this room.... It felt very community in here. 
This "community" encompassed multiple communities, including young and adult members of the Sudanese Australian community and SCM students, brought together by mutual engagement in participatory music-making. As Julia had noticed, this music-making had "no artist audience distinctions" (Turino 2008, 26). The success of this mutual engagement was clearly demonstrated by the excitement of the Sudanese Australian children and young people who, in the new surroundings, with multiple tutors to assist their learning and much greater availability of instruments and equipment than in the LD setting, "were just having a blast" (Julia). It was evident from the interviewed students that they, too, found the experience exciting and fulfilling, as expressed by Julia and Luke.

Julia: It was really rewarding I guess, because... there's nothing like teaching kids that want to learn, I guess that's the main thing. They were all very, very interested and engaged, and you love that.

Luke: I was right in my element, I think. Just jamming, playing, doing things right there, thinking on my feet.... And it was great, they all reacted really positively and I felt pretty comfortable with everything we were doing so I felt right in my, right in my shell. This is what I'm here to do. This is what I've been put on this earth to do.

These accounts of the participatory musical experience resonate with Turino's description of "a kind of heightened, immediate social intercourse" in participatory performance:

when the performance is going well, differences among participants melt away as attention is focused on the seamlessness of sound and motion. At such moments, moving together and sounding together in a group creates a direct sense of being together and of deeply felt similarity... among participants. (Turino 2008,43 )

The rewards for all participants were evident in an exuberant performance of "Count on Me" (Mars et al. 2010, track 9) by Sudanese Australian youth and SCM students at the end of the day at SCM, which was enthusiastically received by the adult audience and followed by plaudits from the LD organizers. This performance (and those in following workshops) was not, however, seen as an endpoint by many of the students.

Joanne: Well you know, you've only just started, you start to see some personalities coming out in kids and you're like, "Oh man." You know, you just see things and you're like, I really want to...

Luke: Continue.

Ella: Watch it grow.

Joanne: Yeah watch it grow.

Such experiences represent what Carson and Westvall constitute as "the beginning of the conversation" $(2016,39)$, which may ultimately result in real changes in cultural responsiveness. Marotta notes that: 
to adopt an intercultural mode of interpretation is to acknowledge that the other is not an end but a means with which to enlarge our understanding and knowledge of ourselves and others. The intercultural mode of understanding would also appreciate that understanding is never complete and final. $(2009,270)$

The need for continued participatory musical experiences to enable evolving development of intercultural understanding was articulated by Clea.

Clea: Even... just being in the moment, immersing yourself within a culture rather than just... like the lectures here are wonderful about different cultures, but it's totally different actually teaching these kids, talking to the kids, there's a definite. We should definitely do it next year, it's very important because, yeah, you can have this many lectures about how cultural diversity is important, blah, blah, blah, but actually being there and you know, chatting, experiencing it yourself....

Luke: Totally different thing.

\section{Conclusion}

In discussing the now-integral ethnomusicological practice of developing knowledge about music through musical participation, Russell and Ingram summarize the many outcomes of musical participation (as simultaneously observed and experienced by ethnomusicological researchers) as including not only the acquisition of knowledge, but the advancement of social connection and the power to "unite diverse individuals in particular contexts of time and space" (2013,1). Through participating musically with Sudanese Australian young people and community members, the SCM students' development of social connectedness appears to have set them on a pathway to cultural connectedness and understanding. Collaborative engagement in such intercultural practices enables members of the receiving society to increase their capacity to "participate in the emotional and aesthetic experiences of cultural strangers, and the resourcefulness with which to make appropriate behavioral adjustments to specific situations and to manage them effectively and creatively" (Kim 2015, 6), thus increasing their cultural competence.

The data presented in this chapter offer only the perspectives of the SCM students and represent only one aspect of a project which had multi-faceted outcomes. Participating in a spatially, physically, sonically and culturally varied community context provided pedagogical challenges for the students which meant that learning about flexibility, teamwork and "going with the flow" was equally important to them. The challenges entailed remind us that the dichotomy between cultures may be institutional and situational, as well as ethnocultural, and such forms of 'cultural dissonance' may be equally unsettling for students but also lead to their ultimate growth of self-knowledge and pedagogical flexibility. The project took place over a relatively short period of time, and therefore, could not be expected to result in a complete change of intercultural understanding or values. There was a level of 
essentialism that remained which, in following iterations of the project, could be addressed by additional levels of mandatory, guided reflection (Marx and Moss 2011). At the same time, there was a marked recognition on the part of some students that difference was not only cultural but also individual, and that there was a need for ongoing experiences and interactions of this kind to further their understandings.

Leh et al. emphasize the importance of developing intercultural competence in teacher education "because teachers are mediators and facilitators of their students' intercultural learning processes and must be not only familiar with factors that are essential in successful intercultural communication but they also have to be intercultural learners themselves" $(2015,7)$. The Bridging Musical Worlds project provided students with opportunities for: developing cultural understandings through meaningful interactions with people; understanding the lived experience of people from refugee backgrounds; understanding cultural mores and their relational and pedagogical implications; and understanding the need for cultural authenticity in repertoire or teaching/learning practices. In so doing, the project offered a vision of approaches that combine applied ethnomusicology and service learning in ways that will be mutually beneficial for teacher-education students and young members of culturally diverse communities in their continued evolution towards intercultural personhood.

Acknowledgements We wish to acknowledge the generosity of Mary Mamour in sharing her musical and cultural expertise with the SCM students, and the LD coordinators and members of the Sudanese Australian LD community for facilitating this project. Financial support was provided by a 2016 Sydney Conservatorium of Music Research Project Grant.

\section{References}

Australian Curriculum, Assessment and Reporting Authority (ACARA). (n.d.). Intercultural understanding. The Australian Curriculum [Online]. http://www.australiancurriculum.edu.au/ generalcapabilities/intercultural-understanding/introduction/introduction. Accessed 20 Nov 2016.

Bartleet, B.-L., Bennett, D., Power, A., Marsh, K., Sunderland, N. (2014). Reconciliation and transformation through mutual learning: Outlining a framework for arts-based service learning with Indigenous communities in Australia. International Journal of Education and the Arts, 15(8) [Online]. http://www.ijea.org/v15n8/. Accessed 21 Nov 2016.

Bartleet, B.-L., Sunderland, N., \& Carfoot, G. (2016). Enhancing intercultural engagement through service learning and music making with indigenous communities in Australia. Research Studies in Music Education, 38(2), 173-191.

Broeske-Danielsen, B. A. (2013). Community music activity in a refugee camp - Student music teachers' practicum experiences. Music Education Research, 15(3), 304-316.

Burnard, P., Mackinlay, E., \& Powell, K. (2016). Introduction and overview. In P. Burnard, E. Mackinlay, \& K. Powell (Eds.), The Routledge international handbook of intercultural arts research (pp. 1-9). New York: Routledge.

Burton, S. L., Westvall, M., \& Karlsson, S. (2012). Stepping aside from myself: Intercultural perspectives on music teacher education. Journal of Music Teacher Education, 23(1), 92-105. 
Campbell, P. S. (2010). Music alive! In the Yakima Valley. International Journal of Community Music, 3(2), 303-308. https://doi.org/10.1386/ijcm.3.2.303_7.

Carson, C., \& Westvall, M. (2016). Intercultural approaches and "diversified normality" in music teacher education: Reflections from two angles. Action, Criticism, and Theory for Music Education, 15(3), 37-52. [Online]. act.maydaygroup.org/articles/CarsonWestvall15_3.pdf. Accessed 15 Jan 2018.

Cassity, E., \& Gow, G. (2006). Making up for lost time: Young African refugees in Western Sydney high schools. Sydney: Centre for Cultural Research, University of Western Sydney.

Charmaz, K. (2014). Constructing grounded theory (2nd ed.). London: Sage.

Cockett, R. (2010). Sudan: Darfur and the failure of an African state. New Haven: Yale University Press.

Corbin, J., \& Strauss, A. (2008). Basics of qualitative research: Techniques and procedures for developing grounded theory (3rd ed.). Thousand Oaks: Sage.

Deardorff, D. K. (2006). Identification and assessment of intercultural competence as a student outcome of internationalization. Journal of Studies in International Education, 10(3), 241-266.

Department of Immigration and Citizenship. (2011). The people of Australia: Australia's multicultural policy. Canberra: DIAC, Australian Government. [Online]. https://www.runnymedetrust.org/uploads/events/people-of-australia-multicultural-policy-booklet.pdf. Accessed 13 Aug 2019.

Dieckmann, S. (2016). Exploring musical acculturation: The musical lives of South Sudanese Australians, Filipino Australians and White Australians in Blacktown. Unpublished doctoral thesis. University of Sydney, Australia [Online]. http://hdl.handle.net/2123/14956. Accessed 20 Nov 2016.

Dunbar-Hall, P. (2009). Ethnopedagogy: Culturally contextualised learning and teaching as an agent of change. Action, Criticism, and Theory for Music Education 8(2): 60-78 [Online]. http://act.maydaygroup.org/articles/Dunbar-Hall8_2.pdf. Accessed 23 Nov 2016.

Dunbar-Hall, P. (2012). Engaging with learning: Shaping pre-service music education students' understandings of pedagogy through international fieldwork. In I. Solomonides, A. Reid, \& P. Petocz (Eds.), Engaging with learning in higher education (pp. 319-332). Faringdon: Libri Publishing.

Emmanuel, D. T. (2005). The effects of a music education immersion internship in a culturally diverse setting on the beliefs and attitudes of pre-service music teachers. International Journal of Music Education, 23(1), 49-62.

Green, L. (2008). Music, informal learning and the school: A new classroom pedagogy. Aldershot: Ashgate.

Hart, J. (2014). Children and forced migration. In E. Fiddian-Qasmiyeh, G. Loescher, K. Long, \& N. Sigona (Eds.), The Oxford handbook of refugee and forced migration studies (pp. 383-393). Oxford: Oxford University Press.

Harwood, E., \& Marsh, K. (2012). Children's ways of learning inside and outside the classroom. In G. E. McPherson \& G. F. Welch (Eds.), The Oxford handbook of music education (pp. 322 340). New York: Oxford University Press.

Higgins, L. (2012). Community music in theory and practice. New York: Oxford University Press. Ingram, C., \& Mamour, M. (2016). Bulls, Balabel, Beyoncé: The musical aesthetics of South Sudanese Australians. Paper presented at the Musicological Society of Australia Annual Conference, University of Adelaide.

Jones, P. M. (2010). Developing social capital: A role for music education and community music in fostering civic engagement and intercultural understanding. International Journal of Community Music, 3(2), 291-302.

Joseph, D., \& Southcott, J. (2009). 'Opening the doors to multiculturalism': Australian pre-service music teacher education students' understandings of cultural diversity. Music Education Research, 11(4), 457-472.

Karlsen, S. (2013). Immigrant students and the "homeland music": Meanings, negotiations and implications. Research Studies in Music Education, 35(2), 161-177. 
Kim, Y. Y. (2015). Finding a "home" beyond culture: The emergence of intercultural personhood in the globalizing world. International Journal of Intercultural Relations, 46, 3-12.

Leh, J. M., Grau, M., \& Guiseppe, J. A. (2015). Navigating the development of pre-service teachers' intercultural competence and understanding of diversity: The benefits of facilitating online intercultural exchange. Journal for Multicultural Education, 9(2), 98-110. https://doi. org/10.1108/JME-12-2014-0042.

LeRiche, M., \& Arnold, M. (2012). South Sudan: From revolution to Independence. London: Hurst.

Marotta, V. (2009). Intercultural hermeneutics and the cross-cultural subject. Journal of Intercultural Studies, 30(3), 267-284.

Mars, B., Lawrence, P., \& Levine, A. (2010). Count on me. On Doo-Wops \& Hooligans [CD]. Los Angeles: Larrabee Recording Studios and Levcon Studios.

Marsh, K. (2005). Going behind the doors: The role of fieldwork in changing tertiary students' attitudes to world music education. In P. S. Campbell, J. Drummond, P. Dunbar-Hall, K. Howard, H. Schippers, \& T. Wiggins (Eds.), Cultural diversity in music education: Directions and challenges for the 21 st century (pp. 37-47). Brisbane: Australian Academic Press.

Marsh, K. (2012). "The beat will make you be courage": The role of a secondary school music program in supporting young refugees and newly arrived immigrants in Australia. Research Studies in Music Education, 34(2), 93-111.

Marsh, K. (2013). Music in the lives of refugee and newly arrived immigrant children in Sydney, Australia. In P. S. Campbell \& T. Wiggins (Eds.), The Oxford handbook of children's musical cultures (pp. 492-509). New York: Oxford University Press.

Marsh, K. (2015). Music, social justice, and social inclusion: The role of collaborative music activities in supporting young refugees and newly arrived immigrants in Australia. In C. Benedict, P. Schmidt, G. Spruce, \& P. Woodford (Eds.), The Oxford handbook of social justice in music education (pp. 173-189). New York: Oxford University Press.

Marsh, K. (2017). Creating bridges: Music, play and wellbeing in the lives of refugee and immigrant children and young people. Music Education Research, 19(1), 60-73. https://doi.org/10. 1080/14613808.2016.1189525.

Marsh, K., \& Dieckmann, S. (2016). Interculturality in the playground and playgroup: Music as shared space for young immigrant children and their mothers. In P. Burnard, E. Mackinlay, \& K. Powell (Eds.), The Routledge international handbook of intercultural arts research (pp. 358-368). Abingdon: Routledge.

Marx, H., \& Moss, D. M. (2011). Please mind the culture gap: Intercultural development during a teacher education study abroad program. Journal of Teacher Education, 62(1), 35-47.

O'Flynn, J. (2005). Re-appraising ideas of musicality in intercultural contexts of music education. International Journal of Music Education, 23(3), 191-203.

Oehrle, E. (1996). Intercultural education through music: Towards a culture of tolerance. British Journal of Music Education, 13, 95-100.

Refugee Council of Australia. (2016). Key facts on the conflict in South Sudan [Online]. http:// www.refugeecouncil.org.au/getfacts/international/south-sudan/. Accessed 25 Nov 2016.

Robinson, K. (2005). Professional development in the diamond fields of South Africa: Musical and personal transformations. In P. S. Campbell, J. Drummond, P. Dunbar-Hall, K. Howard, H. Schippers, \& T. Wiggins (Eds.), Cultural diversity in music education: Directions and challenges for the 21st century (pp. 171-179). Brisbane: Australian Academic Press.

Rowley, J., \& Dunbar-Hall, P. (2013). Cultural diversity in music learning: Developing identity as a music teacher and learner. Pacific-Asian Education, 25(2), 41-50.

Russell, I., \& Ingram, C. (2013). Introduction. In I. Russell, \& C. Ingram (Eds.), Taking part in music: Case studies in ethnomusicology (pp. 1-13). Aberdeen: Aberdeen University Press and European Seminar in Ethnomusicology.

Sæther, E. (2013). The art of stepping outside comfort zones: Intercultural collaborative learning in the international GLOMUS camp. In H. Gaunt \& H. Westerlund (Eds.), Collaborative learning in higher music education: Why, what and how? (pp. 37-48). London: Routledge. 
The University of Sydney. (2016). The University of Sydney 2016-20 strategic plan [Online]. https://sydney.edu.au/dam/intranet/documents/strategy-and-planning/strategic-plan-2016-20. pdf. Accessed 20 Nov 2016.

Turino, T. (2008). Music as social life: The politics of participation. Chicago: University of Chicago Press.

UNHCR. (2016). Global trends: Forced displacement in 2015. United Nations High Commissioner for Refugees [Online]. http://www.unhcr.org/statistics/country/576408cd7/unhcr-globaltrends-2015.html. Accessed 24 Nov 2016.

Westerlund, H., Partti, H., \& Karlsen, S. (2015). Teaching as improvisational experience: Student music teachers' reflections on learning during an intercultural project. Research Studies in Music Education, 37(1), 55-75.

Westoby, P. (2009). The sociality of refugee healing: In dialogue with Southern Sudanese refugees resettling in Australia. Altona: Common Ground Publishing.

Wiggins, T. (2005). Cultivating shadows in the field?: Challenges for traditions in institutional contexts. In P. S. Campbell, J. Drummond, P. Dunbar-Hall, K. Howard, H. Schippers, \& T. Wiggins (Eds.), Cultural diversity in music education: Directions and challenges for the 21st century (pp. 13-21). Brisbane: Australian Academic Press.

Open Access This chapter is licensed under the terms of the Creative Commons Attribution 4.0 International License (http://creativecommons.org/licenses/by/4.0/), which permits use, sharing, adaptation, distribution and reproduction in any medium or format, as long as you give appropriate credit to the original author(s) and the source, provide a link to the Creative Commons licence and indicate if changes were made.

The images or other third party material in this chapter are included in the chapter's Creative Commons licence, unless indicated otherwise in a credit line to the material. If material is not included in the chapter's Creative Commons licence and your intended use is not permitted by statutory regulation or exceeds the permitted use, you will need to obtain permission directly from the copyright holder.

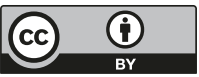

